\title{
Immunohistochemical Expression of EGFR, NF- $\kappa$ B and Cyclin D1 in Sinonasal Inverted Papilloma and Squamous Cell Carcinoma
}

\author{
Pudji Rahaju ${ }^{1}$, Rio Auricknaga Kintono ${ }^{1}$, Ahmad Dian Wahyudiono ${ }^{1}$, Arif Satria ${ }^{2}$, Ferry Sandra ${ }^{3, *}$ \\ ${ }^{1}$ Department of Otorhinolaryngology-Head and Neck Surgery, Faculty of Medicine, Universitas Brawijaya/Dr. Saiful Anwar General Hospital, \\ Jl. Veteran, Malang, Indonesia \\ ${ }^{2}$ Department of Anatomic Pathology, Faculty of Medicine, Universitas Brawijaya/Dr. Saiful Anwar General Hospital, Jl. Veteran, Malang, Indonesia \\ ${ }^{3}$ Department of Biochemistry and Molecular Biology, Division of Oral Biology, Faculty of Dentistry, Universitas Trisakti, J1. Kyai Tapa No.260, \\ Jakarta, Indonesia \\ *Corresponding author. E-mail: ferry@trisakti.ac.id
}

Received date: Feb 16, 2020; Revised date: July 7, 2020; Accepted date: July 13, 2020

\section{Abstract}

$\mathrm{B}$ ACKGROUND: Sinonasal inverted papilloma (SIP), a benign epithelial growth in the sinonasal region with epidermoid epithelial transformation, has been known for its invasiveness, recurrency, and its link with malignancy. Meanwhile sinonasal squamous cell carcinoma (SSCC) is an epithelial malignancy on squamous cells from the sinonasal region. Epidermal growth factor receptor (EGFR), Nuclear Factor $\kappa B$ (NF$\kappa \mathrm{B})$, and Cyclin D1 are factors those might play important role in proliferation of SIP and SSCC. This research was conducted to investigate the expressions of EGFR, NF- $\mathrm{kB}$ and Cyclin D1 in SIP and SSCC.

METHODS: A cross-sectional study by examining the EGFR, NF- $\kappa \mathrm{B}$, and Cyclin D1 immunohistochemical expressions of SIP and SSCC was conducted. Subjects whose blocks were used in this research, were diagnosed as SIP and SSCC at the Otorhinolaryngology-Head and Neck Surgery Clinic, Dr. Saiful Anwar General Hospital. Samples were selected, processed for inmmunohistochemistry, evaluated and statistical analyzed.

RESULTS: Twenty-four SIP and 9 SSCC subjects with their paraffin blocks were selected. Clear immunohistochemical expressions of EGFR, NF- $\mathrm{BB}$, and Cyclin D1 were observed for both SIP and SSCC. Significantly higher immunostaining levels of EGFR $(45.6 \%, p=0.001)$ and NF-KB $(42.2 \%$, $p=0.013)$ were observed in SSCC. Immunostaining levels of EGFR $v s$. NF- $\kappa \mathrm{B}$ were moderately correlated $(p=0.03$, $\mathrm{r}=0.437$ ), while the immunostaining levels of NF- $\mathrm{BB}$ vs. Cyclin D1 were strongly correlated $(p=0.002, \mathrm{r}=0.602)$.

CONCLUSION: Expression of EGFR and NF- $\kappa B$ in SSCC were higher than the EGFR and NF- $\kappa B$ expression in SIP, suggesting that EGFR and NF- $\kappa B$ play important role in sinonasal malignancy.

KEYWORDS: sinonasal, inverted papilloma, SCC, EGFR, NF- $\kappa B$, Cyclin D1

Indones Biomed J. 2020; 12(3): 239-44

\section{Introduction}

Sinonasal inverted papilloma (SIP) is a benign epithelial growth in the nose and paranasal sinus region which are invasive, recurrent, and linked with malignancy.(1) It is one of the 3 Schneiderian papilloma types which is defined by WHO (inverted, fungiform, cylindrical cell type). SIP is a rare tumor with incidence predicted between 0.6-1.5 cases per 100,000 people, and $0.5-4 \%$ of all sinonasal tumors.(2) Symptoms are usually not specific and closely resembles the disease of inflammation. The most common symptoms are one-sided nasal blockage, followed by blood-tinged nasal secretion, headache, facial pain, hyposmia, and epiphora, which are occurred months before diagnosed.(3)

Sinonasal squamous cell carcinoma (SSCC) most commonly occurs in males between 50-60 years old. Patients with SSCC visit health providers with non-specific 
complaints similar with SIP. SSCC occurs from SIP in $2-27 \%$ cases.(4) The sinonasal cavity covered with respiratory epithelium suffers squamous metaplasia that continuous to form squamous intraepithelial neoplasia to SSCC.(5)

Epidermal growth factor receptor (EGFR) is a 170 $\mathrm{kDa}$ protein and a member of the ErbB family from receptor tyrosine kinase (RTK) which promotes cell survival, proliferation, invasiveness. EGFR peptides promote the dimerization of EGFR and phosphorylation of tyrosine residue in its cytoplasmic chain and then promotes Protein kinase $\mathrm{C}$ (PKC), Phosphatidylinositol 3 Kinase (PI3K)/Akt/mechanistic target of rapamycin (mTOR), Src, signal transducers and activators of transcription (STAT), and activates Ras/rapidly accelerated fibrosarcoma (RAF)/ mitogen-activated protein kinase (MAPK)/ extracellular signal-regulated kinases (ERK) kinase (MEK)1/ERK1/2.(6) MAPK has been introduced as important protein in inducing proliferation of tumors.(7,8) Increase expression of EGFR from mutation are obtained in $88 \%$ of SIP cases and $77 \%$ of SSCC.(9)

$\mathrm{NF}-\kappa \mathrm{B}$ is predicted to be the missing link between inflammation and malignancy. $(10,11) \mathrm{NF}-\kappa \mathrm{B}$ is a group of dimer protein binding with a similar binding site called $\kappa \mathrm{B}$ site. NF- $\kappa \mathrm{B}$ promotes some malignancy characteristics including continuous cell proliferation.(12) NF- $\kappa$ B activates Cyclin D1 which promotes cell proliferation through cell cycle modulation. In the early gap $(\mathrm{G}) 1$ phase of the cell cycle, cyclin-dependent kinase $(\mathrm{CdK}) 4$ and/or 6 are activated by Cyclin D. CdK4/6 with Cyclin D1 complex will initiate phosphorylation from retinoblastoma protein $(\mathrm{pRb})$ during early G1 phase. As a result, the transcription E2F responsive genes are needed in cell cycle progression to $\mathrm{S}$ phase to become active.(12)

To our knowledge, investigation in EGFR, NF- $\kappa \mathrm{B}$ and Cyclin D1 of SIP and SCC has never been conducted. Therefore, current research was conducted to widen our view about the correlation of these biomarkers with SIP and SCC.

\section{Methods}

This research was an analytical observation with crosssectional approach by examining the EGFR, NF- $\kappa \mathrm{B}$, and Cyclin D1 immunohistochemical expressions of SIP and SSCC. The research protocol was approved by the Dr. Saiful Anwar General Hospital Research Ethic Commission (Number: 400/013/K.3/302/2019).

\section{Sample Collection and Selection}

Samples were obtained from the paraffin blocks of biopsies/post-operative tissues. Subjects whose blocks were used in this research, were diagnosed as SIP and SSCC at the Otorhinolaryngology-Head and Neck Surgery Clinic, Dr. Saiful Anwar General Hospital, Malang, Indonesia, in the period of January 1, 2016 to December 31, 2018. Subjects those were treated with radiotherapy and/or chemotherapy, were excluded. The blocks were retrieved from pathology laboratory and processed with immunohistochemistry.

\section{Immunohistochemistry}

Paraffin blocks were sliced in 4- $\mu \mathrm{m}$ thickness, deparaffinized and antigen retrieved. After washing with phosphate buffered saline (PBS), the tissue sections were incubated with $3 \%$ hydrogen peroxide to block endogenous peroxidase activity. Tissue sections were incubated with $2 \%$ bovine serum albumin. Then each of the following primary antibodies was applied. For EGFR detection, a mouse monoclonal antibody specific for an epitope mapping between amino acids 1114-1147 within a C-terminal cytoplasmic domain of EGFR of human origin (A-10, Santa Cruz Biotechnology, Dallas, TX, USA) was applied. For NF- $\kappa \mathrm{B}$ detection, a mouse monoclonal antibody raised against amino acids 120-239 mapping at the N-terminus of NF- $\mathrm{B}$ p50 of human origin (E-10, Santa Cruz Biotechnology), was applied. For Cyclin D1, a mouse monoclonal antibody raised against amino acids 1-295 representing full length cyclin D1 of human origin (A-12, Santa Cruz Biotechnology), was applied. After the first antibody, N-Histofine High Stain HRP (MULTI) (Nichirei Biosciences, Tokyo Japan) kit was used. The peroxidase activity was visualized by immersing tissue sections in N-Histofine DAB-2V (Nichirei Biosciences), resulting in a brown reaction product. Tissue sections were finally counterstained with hematoxylin and mounted.

\section{Immunohistochemical Evaluation}

The EGFR, NF- $\kappa \mathrm{B}$ and Cyclin D1 immunohistochemical expressions were examined on 5 fields per slide per subject under a light microscope with 400x magnification by using ImmunoRatio, cross-checked by two trained examiners under supervision of a certified pathologist. Immunostaining levels were delivered in percentage (\%) and statistical analyzed with SPSS Statistics, version 17.0 (SPSS Inc., Chicago, IL, USA) for Chi-Square, MannWhitney, Spearman-Pearson tests. The $p$-value $<0.05$ was considered significant. 


\section{Results}

\section{Subject Characteristic}

Twenty-four SIP and 9 SSCC subjects with their paraffin blocks were selected. General characteristics of subjects can be seen in Table 1. For SIP, most subjects were male, older adult with average age of 50.5 years old, having lower education level, >6-months-to-1-year duration of symptom, and high-risk occupation. Meanwhile, for SSCC, most subjects were also male, older adult with average age of 55.2 years old, and having $>6$-months-to-1-year duration of symptom. Interestingly, higher number of subjects with higher education level and low-risk occupation was

Table 1. General characteristics of subjects.

\begin{tabular}{|c|c|c|c|c|c|}
\hline \multirow{2}{*}{ Characterictic } & \multicolumn{2}{|c|}{ SIP } & \multicolumn{2}{|c|}{ SSCC } & \multirow{2}{*}{ *p-value } \\
\hline & $\mathbf{N}$ & $\%$ & $\mathbf{N}$ & $\%$ & \\
\hline \multicolumn{6}{|l|}{ Gender } \\
\hline Male & 15 & 62.5 & 8 & 88.9 & 0.142 \\
\hline Female & 9 & 37.5 & 1 & 11.1 & \\
\hline \multicolumn{6}{|l|}{ Age Group } \\
\hline \multicolumn{6}{|l|}{ Younger Adult } \\
\hline 25-35 years old & 3 & 12.5 & 1 & 11.1 & 0.407 \\
\hline $36-45$ years old & 6 & 25 & 1 & 11.1 & \\
\hline \multicolumn{6}{|l|}{ Older Adult } \\
\hline 46-55 years old & 5 & 20.8 & 2 & 22.2 & \\
\hline 56-65 years old & 8 & 33.3 & 3 & 33.3 & \\
\hline$>65$ years old & 2 & 8.3 & 2 & 22.2 & \\
\hline \multicolumn{6}{|l|}{ Education level } \\
\hline \multicolumn{6}{|l|}{ Lower education level } \\
\hline Elementary school & 11 & 45.8 & 3 & 33.3 & 0.697 \\
\hline Junior high school & 3 & 12.5 & 1 & 11.1 & \\
\hline \multicolumn{6}{|l|}{ Higher education level } \\
\hline Senior high school & 5 & 20.8 & 2 & 22.2 & \\
\hline Bachelor degree & 4 & 16.7 & 2 & 22.2 & \\
\hline Post graduate degree & 1 & 4.2 & 1 & 11.1 & \\
\hline \multicolumn{6}{|l|}{ Duration of symptom } \\
\hline$\leq 3$ months & 6 & 25 & - & - & 0.467 \\
\hline$>3$ months -6 months & 4 & 16.7 & 3 & 33.3 & \\
\hline$>6$ months -1 year & 9 & 37.5 & 5 & 55.6 & \\
\hline$>1$ year -2 years & 1 & 4.2 & - & - & \\
\hline$>2$ years -3 years & 2 & 8.3 & 1 & 11.1 & \\
\hline$>3$ years -6 years & 1 & 4.2 & - & - & \\
\hline$>6$ years -9 years & 1 & 4.2 & - & - & \\
\hline \multicolumn{6}{|l|}{ Occupation } \\
\hline \multicolumn{6}{|l|}{ High Risk } \\
\hline Farmer & 8 & 33.3 & - & - & 0.286 \\
\hline Leather factory labor & 1 & 4.2 & - & - & \\
\hline Wood factory labor & 1 & 4.2 & 1 & 11.1 & \\
\hline Miner & 2 & 8.3 & - & - & \\
\hline Driver & 1 & 4.2 & 1 & 11.1 & \\
\hline Leather seat maker & - & - & 1 & 11.1 & \\
\hline \multicolumn{6}{|l|}{ Low Risk } \\
\hline Nurse & 1 & 4.2 & - & - & \\
\hline Merchant & 2 & 8.3 & 3 & 33.3 & \\
\hline Housewife & 4 & 16.7 & - & - & \\
\hline Programmer & 1 & 4.2 & - & - & \\
\hline Teacher & 2 & 8.3 & 1 & 11.1 & \\
\hline Office worker & 1 & 4.2 & 2 & 22.2 & \\
\hline
\end{tabular}

*Chi-Square Test, SIP: Sinonasal Inverted Papilloma, SSCC: Sinonasal Squamous Cell Carcinoma. 
observed in SSCC. In more detailed observation, number of the subjects with education level of elementary school was the highest in both SIP (45.8\%) and SSCC (33.3\%). Although there were differences in various characteristics for both SIP and SSCC subjects, there was no significant difference based on the statistical analysis.

\section{EGFR, NF- $\kappa B$, and Cyclin D1 Immunohistochemical Expressions}

Clear immunohistochemical expressions of EGFR, NF$\kappa \mathrm{B}$, and Cyclin D1 were observed for both SIP and SSCC (Figure 1). Higher immunostaining levels of EGFR (45.6\%) and NF- $\mathrm{KB}(42.2 \%)$ were observed in SSCC, while higher immunostaining levels of Cyclin D1 (30.42\%) was observed in SIP (Figure $2 \&$ Table 2). Both the immunostaining levels of EGFR and NF- $\mathrm{KB}$ were significantly higher in SSCC, $p=0.001$ and $p=0.013$, respectively. Based on the correlation test for SIP, the immunostaining levels of EGFR $v s$. NF- $\kappa \mathrm{B}$ were moderately correlated $(p=0.03, \mathrm{r}=0.437)$ (Table 3 ). In addition, the immunostaining levels of NF- $\mathrm{KB}$ vs. Cyclin D1 were strongly correlated $(p=0.002, \mathrm{r}=0.602)$ as well. Meanwhile, the correlation test for SCC did not show any significant correlation.

\section{Discussion}

The average age of SIP (50.5 years old) and SSCC (55.2 years old) subjects of the current study were similar to a previous report with the average age of SIP was 53.72 years old (13), whereas the age of SSCC was between 50 to 60 years old (14). The average duration of symptom in current research were similar with the previous report which was 17.6 months.(13) This long duration was caused by unspecific symptoms suffered by the patients.

In the current research, EGFR was overexpressed in both cases, especially in SSCC. This overexpression was found in esophageal SCC as well, about 59.6 to $76 \%$ cases.(15) There was a moderate positive correlation between immunostaining levels of EGFR and NF- $\kappa B$ in SIP. In oral SCC, it has been reported that there was an increase of NF- $\mathrm{kB}$ expression in the higher stage of oral SCC.(16) Increase of NF- $\kappa \mathrm{B}$ immunostaining levels was also found in current study.

In current research, immunostaining level of Cyclin D1 was a slightly higher in SIP than in SCC.(4) This result is in accordance to the previous report showing that expression of

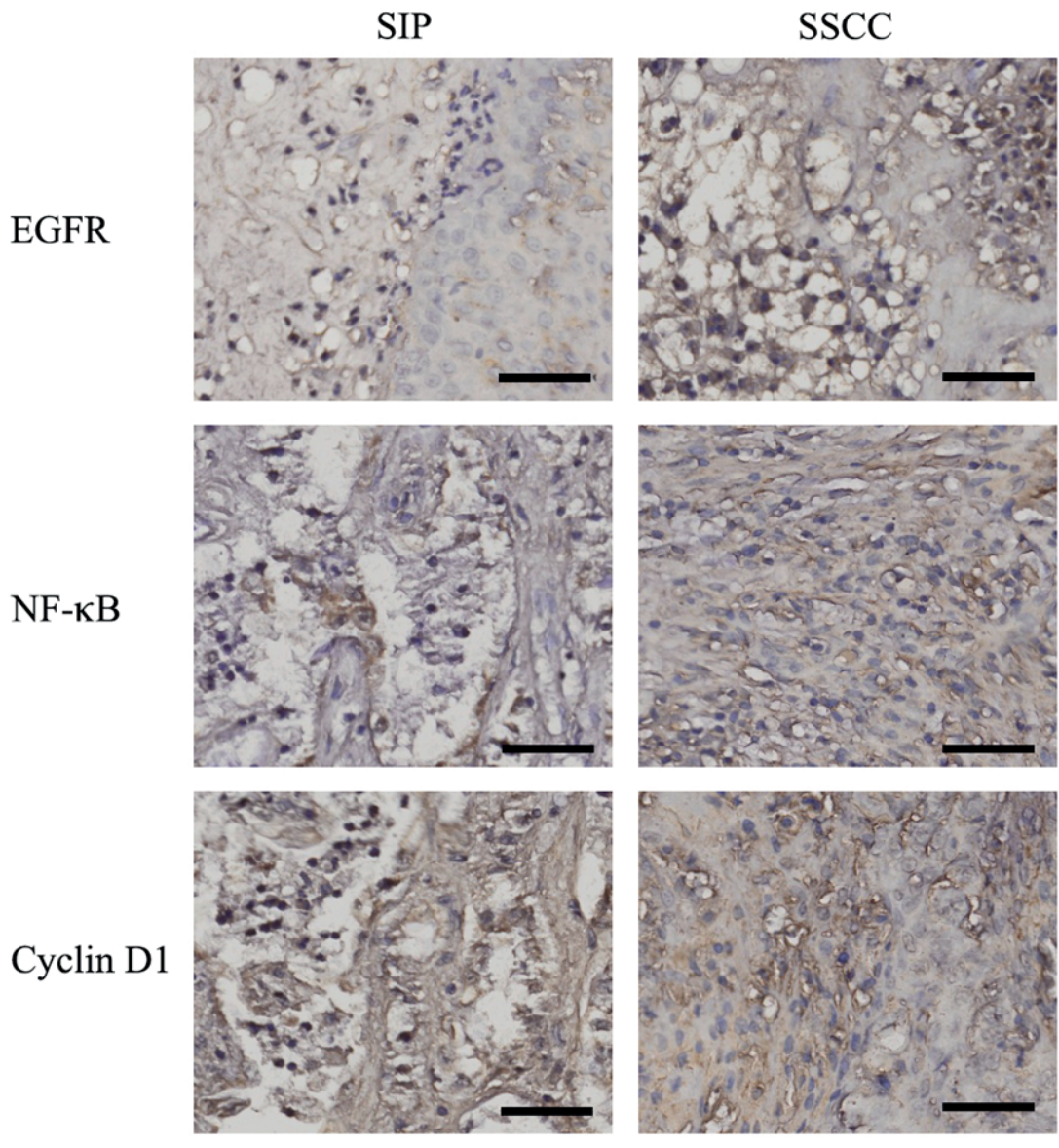

Figure 1. EGFR, NF- $\kappa$ B and Cyclin D1 immunohistochemical expressions of SIP and SSCC. Black bar: $100 \mu \mathrm{m}$. SIP: Sinonasal Inverted Papilloma, SSCC: Sinonasal Squamous Cell Carcinoma. 


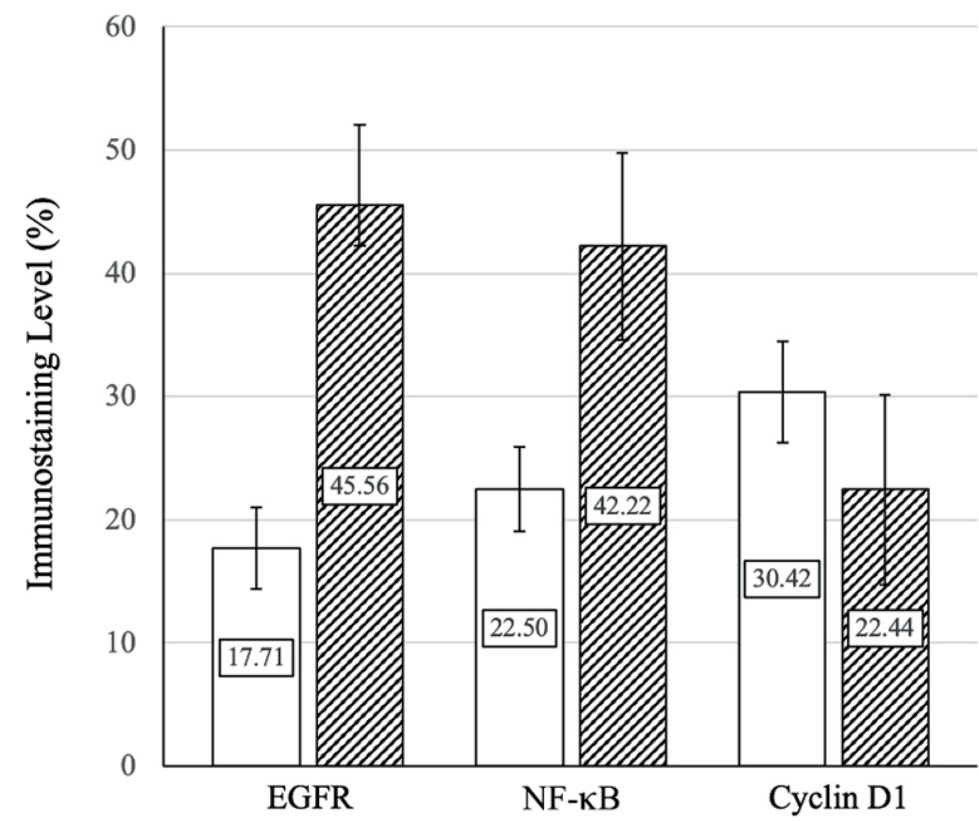

Figure 2. EGFR, NF- $\kappa$ B and Cyclin D1 immunostaining levels of SIP and SSCC. White bar: SIP, striped bar: SSCC. SIP: Sinonasal Inverted Papilloma, SSCC: Sinonasal Squamous Cell Carcinoma.
Cyclin D1 in oral cavity with dysplasia was not significantly different from the one with malignancy transformation.(17) In addition, high expression of Cyclin D1 was reported in low-grade histopathology and early-stage of bladder SCC, whereas low expression of Cyclin D1 were found in highgrade histopathology and late-stage. Low Cyclin D1 was significantly linked with poorer prognosis.(18)

Cell proliferation also could involve some pathway other than Cyclin D1 via Ras-ERK and PI3K-Akt pathway.(19) Higher expression of EGFR, NF- $\mathrm{KB}$ and
Cyclin D1 were related to worse cell differentiation level. Epithel which was organized well in the beginning, lost its characteristics. Thus, it became similar to connective tissue in epithelial-mesenchymal-transition (EMT) which led to malignancy. EGFR was predicted to have a role in initiating EMT related to its mutation.(20) The increased expression of NF- $\mathrm{\kappa B}$ was linked with the activation of the transcription factor of EMT and an increased in Cyclin D1 expression that increased the speed of cell cycle of G1 phase of abnormal cell proliferation.(21)

Table 2. Comparison of EGFR, NF- $\kappa$ B and Cyclin D1 immunostaining levels of SIP and SSCC. SIP: Sinonasal Inverted Papilloma, SSCC: Sinonasal Squamous Cell Carcinoma.

\begin{tabular}{lcccccc}
\hline & \multirow{2}{*}{ Variable } & \multicolumn{7}{c}{ EGFR } \\
\cline { 2 - 7 } & Mean (\%) & Median & SD & Minimum & Maximum & * $p$ - value \\
\hline SIP & 17.71 & 10 & 16.22 & 5 & 60 & 0.001 \\
SSCC & 45.56 & 45 & 19.6 & 20 & 75 & \\
\hline
\end{tabular}

*Mann Whitney Test

\begin{tabular}{lcccccc}
\hline & \multirow{2}{*}{ Variable } & \multicolumn{7}{c}{ NF-kB } \\
\cline { 2 - 7 } & Mean (\%) & Median & SD & Minimum & Maximum & * $\boldsymbol{p}$-value \\
\hline SIP & 22.5 & 17.5 & 16.94 & 5 & 80 & \multirow{2}{*}{0.013} \\
SSCC & 42.22 & 40 & 22.79 & 20 & 80 & \\
\hline
\end{tabular}

*Mann Whitney Test

\begin{tabular}{lcccccc}
\hline & \multirow{7}{*}{ Variable } & \multicolumn{7}{c}{ Cyclin D1 } \\
\cline { 2 - 7 } & Mean (\%) & Median & SD & Minimum & Maximum & * $\boldsymbol{p}$-value \\
\hline SIP & 30.42 & 30 & 20.16 & 5 & 60 & 0.22 \\
SSCC & 22.44 & 15 & 23.1 & 2 & 60 & \\
\hline
\end{tabular}

*Mann Whitney Test 
Table 3. Correlation coefficient of EGFR, NF- $\kappa$ B, and Cyclin D1 immunostaining levels of SIP and SSCC.

\begin{tabular}{|c|c|c|c|c|}
\hline \multirow{2}{*}{ Case } & \multirow{2}{*}{ Variable } & \multicolumn{2}{|c|}{ Correlation Coefficient (r) } & \multirow{2}{*}{$p$-value } \\
\hline & & Spearman & Pearson & \\
\hline \multirow[t]{3}{*}{ SIP } & EGFR $v s . \mathrm{NF}-\kappa \mathrm{B}$ & 0.437 & - & $0.030^{*}$ \\
\hline & NF-кB vs. Cyclin D1 & 0.602 & - & $0.002 *$ \\
\hline & EGFR vs. Cyclin D1 & 0.153 & - & 0.477 \\
\hline \multirow[t]{3}{*}{ SSCC } & EGFR $v s$. NF-кB & - & 0.375 & 0.32 \\
\hline & NF-кB vs. Cyclin D1 & 0.504 & - & 0.17 \\
\hline & EGFR vs. Cyclin D1 & 0.539 & - & 0.13 \\
\hline
\end{tabular}

\section{Conclusion}

Expression of EGFR and NF- $\kappa \mathrm{B}$ in SSCC were higher than the EGFR and NF- $\kappa B$ expression in SIP, suggesting that EGFR and NF- $\kappa B$ play important role in sinonasal malignancy.

\section{References}

1. Sun Q, An L, Zheng J, Zhu D. Advances in recurrence and malignant transformation of sinonasal inverted papillomas. Oncol Lett. 2017; 13: 4585-92.

2. Khandekar S, Dive A, Mishra R, Upadhyaya N. Sinonasal inverted papilloma: A case report and mini review of histopathological features. J Oral Maxillofac Pathol. 2015; 19: 405. doi: 10.4103/0973029X.174644.

3. McCollister KB, Hopper BD, Ginsberg LE, Michel MA. Inverted papilloma: a review and what's new. Neurographics. 2015; 5: 96103.

4. Li W, Lu H, Zhang H, Sun X, Hu L, Wang D. Squamous cell carcinoma associated with inverted papilloma: recurrence and prognostic factors. Oncol Lett. 2020; 19(1): 1082-8.

5. Lewis JS Jr. Sinonasal Squamous Cell Carcinoma: A review with Emphasis on Emerging Histologic Subtypes and the Role of Human Papillomavirus. Head Neck Pathol. 2016; 10: 60-7.

6. Shostak K, Chariot A. EGFR and NF-кB: partners in cancer. Trends Mol Med. 2015; 21: 385-93.

7. Hendarmin L, Sandra F, Nakao Y, Ohishi M, Nakamura N. TNF $\alpha$ played a role in induction of Akt and MAPK signals in ameloblastoma. Oral Oncol. 2005; 41: 375-82.

8. Sandra F, Hendarmin L, Nakao Y, Nakamura N, Nakamura S. Inhibition of Akt and MAPK pathways elevated potential of TNF $\alpha$ in inducing apoptosis in ameloblastoma. Oral Oncol. 2006; 42: 3844.

9. Udager AM, Rolland DCM, McHugh JB, Betz BL, Murga-Zamalloa C, Carey TE, et al. High-frequency targetable EGFR mutations in sinonasal squamous cell carcinoma arising from inverted sinonasal papilloma. Cancer Res. 2015; 75: 2600-6.

10. Sandra F, Kukita T, Tang QY, Iijima T. Caffeic acid inhibits NFkappaB activation of osteoclastogenesis signaling pathway. Indones Biomed J. 2011; 3: 216-22.

11. Hendarmin L, Kawano S, Yoshiga D, Sandra F, Mitsuyasu T, Nakao Y, et al. An anti-apoptotic role of NF- $\kappa \mathrm{B}$ in TNF $\alpha$-induced Apoptosis in an Ameloblastoma Cell Line. Oral Sci Int. 2008; 5(2): 96-103.

12. Karin M, Cao Y, Greten FR, Li ZW. NF-кB in cancer: from innocent bystander to major culprit. Nat Rev Cancer. 2002; 2: 301-10.

13. Zydron R, Marszalek A, Bodnar M, Kosikowski P, Greczka G, Wierzbika $\mathrm{M}$. The analysis of expression of $\mathrm{p} 16$ protein in a group of 53 patients treated for sinonasal inverted papilloma. Braz J Otorhinolaryngol. 2018; 84: 338-43.

14. Bossia P, Farina D, Gatta G, Lombardi D, Nicolai P, Orlandi E. Paranasal sinus cancer. Crit Rev Oncol Hematol. 2016; 98 : 45-61.

15. Ohashi S, Miyamoto S, Kikuchi O, Goto T, Amanuma Y, Muto M. Recent advances from basic and clinical studies of esophageal squamous cell carcinoma. Gastroenterology. 2015; 149: 1700-15.

16. Lee EY, Kang JY, Kim KW. Expression of cyclooxygenase 2, peroxiredoxin I, peroxiredoxin 6 and nuclear factor $\kappa \mathrm{B}$ in oral squamous cell carcinoma. Oncol Lett. 2015; 10: 3129-36.

17. Nikitakis NG, Pentenero M, Georgaki M, Poh CF, Peterson DE, Edwards $\mathrm{P}$, et al. Molecular markers associated with development and progression of potentially premalignant oral epithelial lesions: Current knowledge and future implications. Oral Surg Oral Med Oral Pathol Oral Radiol. 2018; 125: 650-69.

18. Khabaz MN, Buhmeida A, Ghabrah T, Qureshi IA, Butt NS, AlMaghrabi B, et al. Cyclin D1 expression is associated with stage, grade and survival in urinary bladder carcinoma. Int J Clin Exp Med. 2016; 9: 23482-90.

19. Wee P, Wang Z. Review: Epidermal growth factor receptor cell proliferation signaling pathways. Cancers (Basel). 2017; 9: 52. doi: 10.3390/cancers9050052.

20. Lindsey S, Langhans SA. Epidermal growth factor signaling in transformed cells. Int Rev Cell Mol Biol. 2015; 314: 1-41.

21. Pires BRB, Mencalha AL, Ferreira GM, de Souza WF, Morgado-Diaz JA, Maia AM, et al. NF-kappaB Is Involved in the Regulation of EMT Genes in Breast Cancer Cells. PLoS One. 2017; 12: e0169622. doi: 10.1371/journal.pone.0169622. 